\title{
Application of Performance Technology in Educational Technology
}

\section{Yingying Sun}

\author{
School of Information Technology and Communication, Beihua University, Jilin, 132013 \\ wsyy_9@126.com
}

\begin{abstract}
Keyword: Performance; Performance technology; Educational technology; Electronic performance support system
\end{abstract}

\begin{abstract}
With the deepening of the discussion on the educational technology discipline system, people have paid more attention to the performance technology. In this paper, starting from the understanding and research of performance technology and through the brief introduction of it, the connection between educational technology and performance technology is analyzed, and the issue of how to incorporate performance technology into the research scope of educational technology itself is put forward to expand the application research field of educational technology.
\end{abstract}

\section{Introduction}

With the widespread application of modern information technology, the cost of education and cultural communication is becoming higher and higher. The problems of how to avoid unnecessary waste of educational technology input and how to make the limited education investment get the greatest educational development benefit have become the important subjects with strategic significance in the development of contemporary education. Therefore, the performance technology, which was originally born in the enterprise transformation and enterprise training, has become a major subject of the contemporary educational technology and the entire educational development theory and practice frontier.

\section{Performance Technology}

What is Performance Technology? The performance technology emerged in the United States in the 1970s, which was mainly advanced by Drucker, a famous management expert in America. In 1954, aiming at the training for enterprises and other organizations, he used the systematic methods of analysis, design, development and implementation evaluation for the first time to improve the performance level of individuals and organization. After more than 40 years of continuous development, performance technology has become a popular management method in the world, which is widely used in enterprises, hospitals, schools and government agencies. The design, implementation and performance evaluation of performance support systems have become an important issue in this field.

At present, there is no unified definition of performance technology at home and abroad, and the differences between different definitions are also very large. The generally accepted definition is that performance technology is a theoretical and systematic approach to improving organizational and personal performance. Through discovering and analyzing the important organizational or human performance gap, it formulates the plan and scheme that can improve the performance, and designs, develops and implements reasonable intervention measure and evaluates the intervention results, in order to narrow the performance gap and realize performance goals. Performance technology uses the principles and methods from behavioral psychology, instructional system design, organization development and human resource management to design various interventions. It emphasizes that the current performance level and expected level should be analyzed accurately, the reason of performance gap should be identified, the various measures that can improve the performance should be provided, and the management process should be guided and changed to achieve the desired result. 
The Relationship between Performance Technology and Educational Technology. The development history of performance technology and educational technology is very short and they are both very immature. In 1970, the educational technology was defined as "systematic approach", in 1972, it was defined as "domain", in 1977, it was defined as "process", and in 1994, it positioned itself as "theory and practice". At present, most performance technical professionals basically hold the view of "method or process". Performance technology and educational technology have some common fields and pioneers. In the early years of development, they are both devoted to the study and practice of human learning, and the influence and contribution of learning psychologists on the two are not to be neglected. The two are both deeply influenced by Skinner's program teaching thought and they are also influenced by system theory. They insist on systematic method and emphasize systematic analysis. Therefore, the two have a common basis, but there are also some differences. This paper argues that the two have the following differences:

Objects: Everything educational technology does is for individuals, or for optimizing teaching resources. Performance technology takes the individual, enterprise or organization as the object of study. However, educational performance technology not only concerns the effect of individual learning, but also pays more attention to the whole situation of education system and organization.

Target: The goal of educational technical personnel is that students should meet the teaching requirements in terms of skills and knowledge. Instead, performance technicians try to link their work to business needs and outcomes. Educational performance technology is concerned with students' mastery of skills and knowledge while paying more attention to the performance of learning. While caring for individuals, it pays more attention to the implementation of the overall performance of education system and organization.

Application fields/research contents: Educational technology is mainly used in school teaching, which mainly focuses on the teaching process and the optimization of teaching resources. Performance technology is mainly used in enterprises and organizations, which mainly studies the production process, production system, operating environment, etc. Educational performance technology is mainly used in individual learning, school education and the whole education system, which mainly studies the learning process, teaching resources, educational process, education management, etc.

Achievement: The form of the achievement of educational technicians is usually the development of teaching products, the design of teaching programs and the provision of teaching services. Performance technicians do not think that teaching is the whole of a problem solution. They observe and analyze problems, and design and configure the performance solutions that are appropriate to the problem. In addition to teaching products and teaching programs, the educational performance technology has also developed the educational solutions and educational policies.

Talent adaptation field : Educational technicians work in various schools, educational software companies and educational technology organizations. Performance technicians mainly work in large companies, organizations and training centers. However, the educational performance technicians work in various schools, educational institutions and organizations, and educational software companies.

\section{The Practical Application of Performance Technology in Educational Technology}

"Non Teaching Means" are Used to Solve the Problem of Educational Performance. In the use of performance technology methods, the non teaching solutions for performance problems are emphasized, because when we analyze the causes of performance problems deeply, we will find that they are usually caused by the factors other than knowledge, skills and methods of operation, such as employee incentives, working environment, etc. However, these factors can not be improved by means of education and training, so they need to be solved by non teaching means. For educational organizations, the quality of teaching is the most important indicator to measure the performance of educational organization. Therefore, the improvement of teaching performance is the most concern of all educational organizations. In the teaching activity or in the job training, we should combine the performance technology and teaching design thinking organically to realize the complementary 
advantages, so as to make teaching activities and job training more productive.

Electronic Performance Support System. The electronic performance support system is basically carried out with the performance technology. As a performance support tool guided by performance technology, it can be regarded as the application of performance technology. Electronic performance support systems are commonly used in enterprise organizations to support employee performance and work training. The application of it in the school education environment can be divided into three parts according to different use objects. They are respectively the "student's learning support system" which aims at improving students' learning performance, the " teacher's teaching support system" which aims at improving the quality of teachers and the quality of teaching, and the "school administrative support system" which assists in improving school administration quality and overall performance. At present, the research focus of this field is the research and development of web-based teacher performance support system. Although there are many ways to improve the teaching performance of teachers, the research of web-based electronic performance support system for teachers should be a very worthwhile way to try. If it can provide any relevant required information, tools and methods in teaching for teachers, then teachers can use or reference conveniently. And also if it can provide query and search help for teacher's science research through network, the teachers' professional knowledge and teaching efficiency will be improved, thus the goal to improve teachers' work performance can be realized.

\section{The Future of Performance Technology}

At present, it is the best period for the development of educational technology, and it is also a critical period. When we study the application of performance technology in educational technology, we should pay attention to the following problems:

The First One is to Find the "positioning" and Deal with the Relationship between "Reference and Innovation". We should learn(not copy) from all the advanced ideas, theories and methods of foreign countries to transform the relevant theories, creatively solve problems of education and teaching in china, and promote educational modernization according to the situation of our country and the need of educational technology development. Also we should prevent all westernization and generalization, so as to establish a new theory system of educational technology subject with Chinese characteristics facing the twenty-first century.

The Second One is to Pay Attention to Link Theory with Practice. The application of performance technology in educational technology is a new research subject. There are many problems to be solved both theoretically and practically. In the process of studying and solving problems, we should adopt the scientific research method, and take the correct educational philosophy and the philosophy of science and technology as the guide to establish a comprehensive view of educational technology. In the theoretical research, we should seize the essence of things, sum up the results of the law, closely link with the actual situation, and study the case. We shouldn't just study from theory to theory or from Internet to Internet, but should contact with practical problems. In practical research, we should clear the guiding ideology and carry out scientific and normative research under the guidance of relevant theories. Also we should avoid following the trend, and avoid mindless and shallow repetitive work.

The Third One is to Deal with the Relationship between "Inheritance and Development". The rapid development of discipline of our educational technology in a short period of more than ten years benefits from the firm foundation laid by audio-visual education. Experience and lessons gained by audio-visual education, the theoretical achievements and practical achievements summarized by it, and the complete organization and a large number of professional staff established by it are the inexhaustible source of performance technology research. It is a glorious and arduous task for our educational technology workers to inherit the fine tradition of audio-visual education and establish a disciplinary system of educational technology with Chinese characteristics. 


\section{Pay Attention to the Training of Front-line Teachers}

The development of educational technology is not just a matter of educational technology professionals. Only when teachers have grasped the basic knowledge and methods of educational technology and transformed them into the ability and belief to teach well, can educational technology be truly popularized. Therefore, we should adopt new ideas, new methods and new forms to effectively improve the quality of educational technology of the front-line teachers. In order to accomplish this task, it is necessary to establish educational technology standards and norms, study the evaluation system, and establish and perfect the support and service system for teachers.

\section{Acknowledgements}

This paper is one of the research achievements of education and teaching research topic "Optimization and Research of "Educational Technology Foundation" Course Teaching Resources for Normal Students” of Beihua University in 2014.

\section{References}

[1] Y.Y.Sun, C.S.Zhang and F.Lv: Research on the Ability Cultivation of the Digital Media Technology of Normal College Students[J], China Educational Technology and Equipment, 2014(24).(In Chinese)

[2] Y.Y.Sun: Exploration and Practice of Educational Informatization[J], Education and Vacation, 2012(11).(In Chinese) 